\title{
Evaluating Person-Oriented Measures to Understand Sexuality with Cerebral Palsy: Procedures and Applications
}

\author{
Tinashe Dune ${ }^{1} \&$ Elias Mpofu ${ }^{2}$ \\ ${ }^{1}$ Interprofessional Health Science, School of Science and Health, University of Western Sydney, Penrith 2751, New \\ South Wales, Australia \\ ${ }^{2}$ Rehabilitation Counselling, Faculty of Health Science, University of Sydney, Faculty of Health Sciences, Lidcombe \\ 2141
}

Correspondence: Tinashe Dune, Interprofessional Health Science, School of Science and Health, University of Western Sydney, Penrith 2751, New South Wales, Australia.

Received: June 1, 2015.

Accepted: June 15, 2015.

Available online: June 25, 2015

doi:10.11114/ijsss.v3i4.903

URL: http://dx.doi.org/10.11114/ijsss.v3i4.903

\begin{abstract}
This paper is based on a research which explored sexual scripts in the lives of people with cerebral palsy. To assess the utility of the study protocol, aimed at exploring the relative salience of public, interactional and private sexual scripts as described by people with cerebral palsy, a pilot study was conducted. This paper discusses the development and results of the pilot study used to test the accessibility and trustworthiness (credibility, transferability, dependability, and confirmability) of the study protocol. This paper also outlines the utilization of the pilot study in the modification of the final study protocol. Consistent with the aims of the pilot study networks were established which facilitated recruitment of individuals within the sampling frame and also provided participants for the main study. The trustworthiness of the study was confirmed through an assessment of the credibility, transferability, dependability and confirmability of the interview guide. Transferability was achieved through the provision of evidence of the analytic process which may allow other researchers to repeat, as closely as possible the procedures of this project. Dependability and confirmability of the data collection, analysis, theory production and the level to which the study's findings are supported by the collected data were ensured through the employment of an independent audit of the research methods by a competent peer. The pilot study confirmed the availability of participant networks as well as the accessibility and trustworthiness of the study protocol. Pilot studies continue to be a medium to test research methodology and apply necessary amendments in order to conduct larger studies.
\end{abstract}

Keywords: Pilot study, cerebral palsy, sexuality, sexual scripts, trustworthiness, qualitative methods

\section{Introduction}

Sexuality, whilst, acknowledged as a key aspect of human sexuality is often discussed within mainstream society as an afterthought for people living with chronic illness and/or disability (Dune, 2014a). Yet, much disability research indicates that sexuality is of fundamental importance to people with disabilities. For instance, constructions of sexuality and disability have been discussed widely by scholars across a number of fields. (Brown, 1988; Chance, 2002; Dune \& Shuttleworth, 2009; Earle, 1999; Joseph, 1991; Sanders, 2007; Stevens, Steele, Jutai, Kalnins, Bortolussi \& Biggar, 1996; Taleporos \& McCabe, 2005; Wiwanitkit, 2008; Xenakis \& Goldberg, 2010). Yet, the ways in which people with disabilities acquire information, negotiate and think about sexuality and/or sexual behaviour is not well understood. Further, there has been relatively little research on how people with cerebral palsy construct their own sexuality and the salience of the socio-sexual schema which are involved in this process.

Canonical sexuality research proposes that human sexuality is shared, understood and internalized via sexual scripts (Simon \& Gagnon, 1986, 1987, 2003). It is unclear however if these same pathways are salient for people with chronic illness and disability. Further, if they are important factors in sexual constructions with disability, how significant is each factor in the ways that people with disabilities understand their sexuality? Given these epistemological gaps, this study aimed to address three questions; 1) the relative salience of public, interactional and private sexual schema in the construction of sexuality for people with cerebral palsy, 2) how people with cerebral palsy construct sexual participation, and particularly sexual spontaneity and, 3) how people with cerebral palsy describe their 
sexuality.

This project utilized a hermeneutic phenomenological approach to explore these questions. In doing so, this study helps fill the gap between how sexuality and disability is constructed external to the individual and how the individual constructs their own sexuality. For this research, seven in-depth, semi-structured interviews were conducted with five men and two women with moderate to severe cerebral palsy.

Participant data indicated that how people with cerebral palsy perceive sexual experiences with others (interactional) is the most influential factor in the construction of their sexuality (Dune, 2013). Public influences were cumulatively the second most important factor in the construction of sexuality by people with cerebral palsy (Dune, 2014b). Finally, private influences were cumulatively the least influential factor in the construction of their sexuality (Dune, 2014a). Sexual spontaneity primarily was a derivative of sexual exploration. Furthermore, participants defined sexual spontaneity as liberating and allowed them to experience their sexuality with others relatively independent of normative sexual scripts. Participants also described their sexuality primarily in terms of major transitions and experiences which involved others.

Based on the findings sexual theory needs to be more cognizant of sexual agency as primary in the construction of sexuality with significant disability. In addition, healthcare providers and people with cerebral palsy are likely to be successful partners in sexual health when they promote positive and agentic constructions of sexuality with significant disability. The findings emphasize that people with cerebral palsy are cognizant and intelligent agents in the construction of their sexuality. Their articulations, understandings and descriptions of their sexuality demonstrate their interest and awareness in their sexuality and issues related to it. People with cerebral palsy are sexual agents and beings who empower themselves (Dune, 2013).

Considering the lack of prior research in the area a pilot study was employed in order to test the accessibility and trustworthiness (credibility, transferability, dependability, and confirmability) of the study protocol in exploring constructions of sexuality with disability. This research, its findings and subsequent conclusions may have been irrelevant or more difficult to come by of this preliminary work had not been done. Thus, the current paper discusses the procedures used in the design and application of the pilot study and presents key lessons learnt.

\section{Research Design}

Qualitative methodology was used for this investigation in order to compliment the hermeneutic phenomenological framework upon which this study was based. Hermeneutic phenomenology aims to answer questions about the meaning of being, the self and self-identity (van Manen, 2002). According to McCarthy (2010) in order to better understand psycho-social experiences of impairment and disability researchers should effort to explore the lived experiences of their participants.

Ajjawi and Higgs (2007) stated that in the context of hermeneutic phenomenological inquiry, qualitative methodology "enabled access to a phenomenon that is often subconscious and provided a means of interpreting participants' experiences of personal learning journeys" (p. 612). A qualitative methodology which aimed to explore phenomena in its nuanced richness was appropriate for this study whose goal was to understand insider perspectives of constructions of sexuality by people with cerebral palsy. As such, the study intended to employ person-oriented measures to investigate participants' insider perspectives.

Insider perspectives refer to individual participant interpretations of a construct or phenomena (Liamputtong, 2010; Silverman, 2009). An insider perspective allows for the exploration of concepts from the participants own perspective(s). Rich descriptions result from qualitative exploration of insider perspectives. In turn rich descriptions allow for interpretative conceptualizations important for comprehensive understandings (Mayoux, 2006). In order to facilitate this process in-depth interview techniques were used as interactive conversations between the investigator and participants to explore contextual, interactive and personal sexual scripts. In order to do so successfully this project and its procedures were assessed for trustworthiness.

\subsection{Issues of Trustworthiness within a Qualitative Study}

Almost two decades ago, Lincoln and Guba (1985) posed the question: "How can an inquirer persuade his or her audiences that the research findings of an inquiry are worth paying attention to?" (p. 290). This question highlights the importance of a trustworthy account of human experiences and their utility. According to Patton (2001) trustworthiness is a factors which every qualitative researcher should concern themselves with while designing a study, analyzing results and judging the quality of the study. In qualitative paradigms the term "trustworthiness" encompasses "credibility," "transferability," "dependability," and "confirmability" (Tipping, Scholes \& Cox, 2010). Credibility is the evaluation of how well the study's findings represent a sound conceptual interpretation of the data which comes from participant data (Hoffman, 2010). Transferability is the potential of the study's findings to transfer to other settings. 
Dependability is the assessment of the quality of the collective processes which include data collection, analysis, and theory production. Finally, confirmability is a gauge of the level to which the study's findings are supported by the collected data (Tipping, Scholes \& Cox, 2010). These qualities are important in qualitative inquiry as they affirm the value and utility of one's research findings (Patton, 2001).

\section{Pilot Study}

A pilot study was conducted to pretest the study protocol; including the establishment of networks, assessing accessibility, assessing trustworthiness and the amendment of issues identified. According to van Teijlingen, Rennie, Hundley and Graham (2001) "advantages of conducting a pilot study is that it might give advance warning about where the main research project could fail, where research protocols may not be followed, or whether proposed methods or instruments are inappropriate or too complicated" (p. 1). As such, the goals of the pilot study were to:

1. Establish the networks in which to locate possible participants with cerebral palsy who fulfilled the inclusion criteria (see Table 1).

2. Assess the cognitive and procedural accessibility of the interview guide (see Figure 1).

3. Assess the trustworthiness of the interview guide as a tool for understanding constructions of sexuality as created and experienced by people with cerebral palsy.

a. Assess whether people with cerebral palsy discuss their sexuality in ways that mirror public, interactional and private sexual constructs (credibility).

b. Assess whether the data collected through the interview guide can be found in similar populations of people with cerebral palsy (transferability).

c. Assess whether the data collection, data analysis and theory generation processes of the study were consistent and repeatable (dependability).

d. Assess the influence of the researcher and/or their bias on the study's findings in relation to the data collected (confirmability).

4. Anticipate and amend any logistical and procedural issues or limitations related to the study.

\subsection{Sampling Frame}

The sampling frame comprised adults living with moderate to severe cerebral palsy within Australia and Canada. In this study moderate cerebral palsy was defined according to levels three, four and five of the Gross Motor Function Classification System (Palisano, Rosenbaum, Walter, Russell, Wood \& Galuppi, 1997). In addition, adults with cerebral palsy who were subscribers of disability newsletters, magazines and/or who were members of Cerebral Palsy groups and associations in Australia and Canada were specifically recruited.

The sampling frame for this study was inclusive a variety of living arrangements. For instance, individuals who lived with their families, with their friends, within residential institutionalizations, those who required daily assistance from others and those who did not require daily assistance from others were included. Individuals under 18 years of age, with mild symptoms of cerebral palsy or those with intellectual impairment(s) were not included in the sampling frame. This study sought out participants with moderate to severe cerebral palsy regardless of habitation, with whom they lived, ethnic or cultural background, religious affiliation, sexual orientation or nationality.

Considering the many configurations and the continuum of severity of cerebral palsy each participant will possess different physical and mental capacities. In this regard, it was important to ensure that individuals included in the sampling frame could be accommodated by the study.

\subsection{Participants}

In selecting participants for the pilot study, consideration was given to demographics, levels of mobility and acquired assistance, socio-economic status, medical interventions, living arrangements and sexual profile (also see Table 1 for a summary of participant profiles). These factors were important to study as they provided contextual information about participants and their perspectives. Data on these variables would allow a comprehensive analysis of participant's experiences of disability and sexuality.

\subsubsection{Demographics}

A convenience sample of three adults with cerebral palsy (23 to 36 years of age) and living in New South Wales, Australia participated in the pilot study. Of these three participants one was female and the remaining two were male. The female participant had spastic paraplegic cerebral palsy (SPCP), one male had spastic quadriplegic cerebral palsy (SQCP) and the other male participant had ataxic quadriplegic cerebral palsy (AQCP). SPCP is characterized by the 
lower extremities being affected with little to no upper-body spasticity. People with SQCP are least likely to be able to walk due to impairment of all four limbs. If people with SQCP can or want to walk their muscles are too tight making it too much effort to do so. AQCP is characterized by difficulty with dexterity and precise use of all limbs and appendages. For all participants mobility was moderately or severely affected by impairment. It was important to understand how participant demographics would likely influence how participant's harmonized their experiences with impairment and disability with their sexuality.

\subsubsection{Mobility and Assistance}

The two male participants required the use of a mechanized wheelchair to assist in mobility and the female participant often used crutches to assist in mobility. One of the male participants had a noticeable oral/facial muscle impairment which affected eating (mastication), speaking (annunciating words and expressing thoughts and opinions), breathing and drinking (sucking and swallowing). The male participants had severe cerebral palsy which required significant daily assistance in order to complete quotidian tasks. As such, they enlisted the help of their parents (most often their mothers), paid personal care attendants and on the occasion friends and other family members to complete daily activities. The quality of paid care they received was also facilitated by their ability to access funding from social services. In relation to cerebral palsy, the behavioural profile of the participants can be characterized as typical. Being aware of participant's behavioural profiles facilitates understanding of the influence disability has on how people with cerebral palsy construct their sexuality.

\subsubsection{Socio-Economic Status}

All participants for the pilot study were Caucasian Australians and of middle to upper-middle class background. The three participants had received tertiary education in Australia and pursued activities within their fields of study. The male participants were actively involved in sporting clubs, community groups and leisure activities while the female participant had full-time employment in addition to community, sport and leisure activities. In this regard participants had access to social involvement. However, due to restrictions in mobility due to infrastructure and impairment all participants had experienced medical interventions to facilitate mobility. Although participants of the pilot study could be classified as privileged they may share some of the same socio-cultural experiences as individuals from lower (or higher) socio-economic status (i.e., ethnicity, access to basic health services, citizens of a developed country and access to similar educational opportunities).

\subsubsection{Medical Intervention}

All participants had experienced significant medical intervention through major surgeries during childhood and early adolescence. A history of medical health care meant participants would likely be reliably retained. The medical interventions they experienced required all of the participants to endure a number of long recovery periods, extended stays in medical institutions and life-long rehabilitative commitments. These experiences and commitments meant that some of the participants felt that rehabilitative activities were necessary before and after sexual encounters to facilitate ease of movement during sexual activities or to prevent stiffness or pain afterwards. Due to differing levels of physical mobility each participant's living arrangements complimented their abilities and facilitated independence.

\subsubsection{Living Arrangements}

In terms of living arrangements the youngest male participant lived in an independent living facility at the time of their interview. The female participant lived with her partner at the time of the interview. The eldest male participant reported that he lived at home with his mother and had lived with his parents for the most of his life. Each participant had engaged in different sexual activities prior to the time of the interview. While privacy may be limited for people with moderate to severe Cerebral Palsy due to the daily and consistent involvement of caregivers projections about the correlation between living arrangements and sexual activity cannot be made.

\subsubsection{Sexual Profile}

All participants identified as heterosexual. One of the male participants indicated that he had had engaged in sexual activities with men. Of the three participants interviewed only the female participant was in a steady sexually intimate relationship. She described her partner as physically and mentally typical. The male participant with Spastic Quadriplegic cerebral palsy had engaged in sexual activities and intimacy with himself and others but had not yet been involved in a steady sexually intimate relationship. Prior to the interview the male participant with AQCP had been in a steady sexually intimate relationship for four years. As per the pilot study participants, people with cerebral palsy do not experience sexuality in the same way(s). The heterogeneous nature of sexual experiences for this group suggests that the pilot study will capture information which mirrors experiences of sexuality of potential main study respondents. 
Table 1. Pilot Study Participant Summary

\begin{tabular}{|l|l|l|l|l|l|l|l|}
\hline Participant & Sex & $\begin{array}{l}\text { Type of Cerebral } \\
\text { Palsy }\end{array}$ & $\begin{array}{l}\text { Assistive Devices } \\
\text { or Services }\end{array}$ & $\begin{array}{l}\text { Socio-economic } \\
\text { Status, education } \\
\text { and ethnicity }\end{array}$ & Medical Interventions & $\begin{array}{l}\text { Living } \\
\text { Arrangements }\end{array}$ & Sexual Profile \\
\hline Participant 1 & Female & $\begin{array}{l}\text { Spastic Paraplegic } \\
\text { Cerebral Palsy } \\
\text { (moderate) }\end{array}$ & Crutches & $\begin{array}{l}\text { Upper-middle class, } \\
\text { tertiary education, } \\
\text { Caucasian } \\
\text { Australian }\end{array}$ & $\begin{array}{l}\text { Major muscul oskeletal } \\
\text { surgery during childhood } \\
\text { and adolescence. } \\
\text { Rehabilitative m aintenance. }\end{array}$ & $\begin{array}{l}\text { Lived with her } \\
\text { partner } \\
\text { independently }\end{array}$ & $\begin{array}{l}\text { Heterosexual, in a } \\
\text { long term sexual } \\
\text { relationship at time } \\
\text { of interview }\end{array}$ \\
\hline Participant 2 & Male & $\begin{array}{l}\text { Spastic Quadriplegic } \\
\text { Cerebral Palsy (severe) }\end{array}$ & $\begin{array}{l}\text { Mechanized } \\
\text { wheelchair, daily } \\
\text { personal assistance } \\
\text { from others }\end{array}$ & $\begin{array}{l}\text { Middle class, } \\
\text { tertiary education, } \\
\text { Caucasian } \\
\text { Australian }\end{array}$ & $\begin{array}{l}\text { Major musculoskeletal } \\
\text { surgery during childhood } \\
\text { and adolescence. } \\
\text { Rehabilitative maintenance. }\end{array}$ & $\begin{array}{l}\text { Lived with his } \\
\text { mother in his } \\
\text { family's home }\end{array}$ & $\begin{array}{l}\text { Heterosexual, } \\
\text { sexually active, no } \\
\text { history of sexually } \\
\text { intimate } \\
\text { relationships }\end{array}$ \\
\hline Participant3 & Male & $\begin{array}{l}\text { Ataxic Quadriplegic } \\
\text { Cerebral Palsy (severe) }\end{array}$ & $\begin{array}{l}\text { Mechanized } \\
\text { wheelchair, daily } \\
\text { personal assistance } \\
\text { from others }\end{array}$ & $\begin{array}{l}\text { Middle class, } \\
\text { tertiary education, } \\
\text { Caucasian } \\
\text { Australian }\end{array}$ & $\begin{array}{l}\text { Major muscul oskeletal } \\
\text { surgery during childhood } \\
\text { and adolescence. } \\
\text { Rehabilitative maintenance. }\end{array}$ & $\begin{array}{l}\text { Lived in an } \\
\text { independent living } \\
\text { facility }\end{array}$ & $\begin{array}{l}\text { Heterosexual, } \\
\text { history of long } \\
\text { term sexually } \\
\text { intimate } \\
\text { relationship }\end{array}$ \\
\hline
\end{tabular}

\section{Establishing Networks for Participant Recruitment}

To establish networks for the recruitment of eligible participants the four sources were: 1) requesting participation from major cerebral palsy organizations in Australia, 2) disability/Cerebral Palsy newsletter or magazines, 3) Sydney-based community centres or advocacy groups and,4) snowballing (see Table 2). A multipronged recruitment strategy was piloted to allow members of different communities the opportunity to participate in the study. In doing so, the study could capture the experiences and perspectives of sexuality from a variety of individuals.

People with cerebral palsy are a hidden population in that it may be difficult to gain access to members without being a part of the community (Rhodes, Bowie \& Hergenrather, 2003). As such, diverse but complementary approaches to participant recruitment, such as those used in this study, are recommended for recruiting hard to reach or hidden populations (Ompad et al., 2008).

\subsection{Major Cerebral Palsy Organizations}

First, major cerebral palsy organizations in Australia were identified through a Google search. Of the many results displayed only those which only focused on cerebral palsy in Australia were of interest. The researcher then telephoned the major cerebral palsy foundations, associations and organizations (i.e., Cerebral Palsy Foundation, Spastic Centre, Cerebral Palsy Australia, The Centre for Cerebral Palsy and Cerebral Palsy League) in Australia and requested their participation in the project. Of the five organizations contacted in Australia the Cerebral Palsy Foundation and the Spastic Centre agreed to participate in the promotion of the study to their members/subscribers.

\subsection{Disability Newsletters and Magazines}

A search through Google in Australia for major disability newsletter or magazines which catered to people with cerebral palsy was also carried out. Those which were based in New South Wales, Australia were shortlisted. The researcher then telephoned each newsletter and requested their participation in the project. Of the four newsletters contacted; 1) The Scene Newsletter, 2) SX News, 3) Warringah Disability Newsletter and 4) IDEAS Newsletter, The Scene and the Warringah Disability Newsletter were to only two who agreed to facilitate this study and ran the study advertisement for one year and six months respectively.

\subsection{Community and Advocacy Groups/Centres}

Google community and advocacy groups/centers which catered specifically to people with cerebral palsy were searched. As there was a large number of results only those organizations in Sydney, New South Wales, Australia which had had programs specifically designed for or which catered to people with cerebral palsy were contacted (Disability Services City of Sydney, Mary McDonald Activity Centre, Harry Jensen Activity Centre, St. Helen's Community Centres, Cliff Noble Activity Centre and Ron Williams Activity Centre). The researcher subsequently sent each facility a letter requesting if the researcher could present the project to their constituents with cerebral palsy. The letter was also followed up by a telephone call and/or email to ensure the letter had been received and considered. Of the six community centers contacted all indicated that they no longer had active disability programs/gatherings and were therefore unable to participate. 


\subsection{Snowballing}

The snowballing technique was utilized at the end of each participant's interview, to identify others they knew who met the eligibility criteria, and if so, whether she or he would be willing to give that person a copy of the participant information sheet. The investigator did not know the identity of this person, and the interviewee did not know if that person agreed to participate in the project or not.

Table 2. Establishing Cerebral Palsy Networks Summary

\begin{tabular}{|c|c|c|c|c|}
\hline & \multicolumn{4}{|c|}{ Strategy } \\
\hline Steps & $\begin{array}{l}\text { Cerebral Palsy Organizations in } \\
\text { Australia }\end{array}$ & $\begin{array}{l}\text { Disability Newsletters and Magazines } \\
\text { in Australia }\end{array}$ & $\begin{array}{l}\text { Community Centres and } \mathrm{A} \text { dvocacy } \\
\text { groups catering to people with Cerebral } \\
\underline{\text { Palsy }}\end{array}$ & Snowballing \\
\hline 1 & Google search and telephone calls & Google search and telephone calls & Google search and telephone calls & $\begin{array}{l}\text { Asking participants if they knew someone } \\
\text { who could be included in the sampling } \\
\text { frame }(x=3)\end{array}$ \\
\hline 2 & $\begin{array}{l}\text { Refined to major organizations which } \\
\text { cater exclusively to people with } \\
\text { Cerebral Palsy and their families in } \\
\text { Australia }(x=5)\end{array}$ & $\begin{array}{l}\text { Refined to newsletters which catered } \\
\text { to people with Cerebral Palsy } \\
\text { particularly in New South Wales ( } x= \\
\text { 4) }\end{array}$ & $\begin{array}{l}\text { Refined to community centres in Sydney, } \\
\text { New South Wales, Australia that had } \\
\text { (had) disability programs/events for } \\
\text { people with Cerebral Palsy }(\mathrm{x}=6)\end{array}$ & $\begin{array}{l}\text { Giving the participant a copy of the } \\
\text { Snowball Participant Information Sheet }\end{array}$ \\
\hline 3 & Telephoned all 5 organizations & Tel ephoned all 4 organizations & $\begin{array}{l}\text { Letter sent to all } 6 \text { organizations. Email } \\
\text { or phone call used to follow-up }\end{array}$ & $\begin{array}{l}\text { The participant gives the Snowball } \\
\text { Participant Information Sheet to someone } \\
\text { they know }\end{array}$ \\
\hline 4 & $\begin{array}{l}\text { Posted advertisement for the study on } \\
\text { organization website or within their } \\
\text { newsletter }(s)(x=2)\end{array}$ & $\begin{array}{l}\text { Posted advertisement for the study on } \\
\text { within hardcopy newsletter }(s) \text { and } \\
\text { newsletter webpages }(\mathrm{x}=2)\end{array}$ & $\begin{array}{l}\text { None of the community centre had the } \\
\text { resources or participation in the disability } \\
\text { programs to participate }\end{array}$ & $\begin{array}{l}\text { The individual the participant gives the } \\
\text { Snowball Participant Information Sheet to } \\
\text { contacts the researcher }\end{array}$ \\
\hline $\begin{array}{l}\text { Resultant } \\
\text { Participants }\end{array}$ & 1 & 2 & 0 & 0 \\
\hline
\end{tabular}

\section{Assessment of the Cognitive and Procedural Accessibility of the Interview Guide}

To ensure that the interview guide was accessible to all potential participants Fry's readability analysis was applied to assess cognitive accessibility. Procedural accessibility was assessed through the provision of different methods for people with cerebral palsy to participate.

\subsection{Readability analysis}

The interview guide was assessed using Fry's (1968) readability graph (Figure 1) which includes reading/grade levels from early childhood to adulthood. To gauge the readability of a text one must calculate the number of syllables and sentences for three 100-words passages to compute a result in school years. Considering that the interview guide is organized as a series of questions, to create 100-word passages several questions were calculated together and each question was treated as an individual sentence. Of the 261 words assessed, 26 sentences/questions and approximately 500 syllables the pilot study interview guide lies between a grade 5 and grade 7 level of reading. Considering that all the participants successfully completed tertiary studies their reading level would exceed that of a $5^{\text {th }}, 6^{\text {th }}$, or $7^{\text {th }}$ grade pupil. As such, cognitive accessibility could reasonably be assumed. 


\section{Fry Graph for estimating Reading Ages (grade level)}

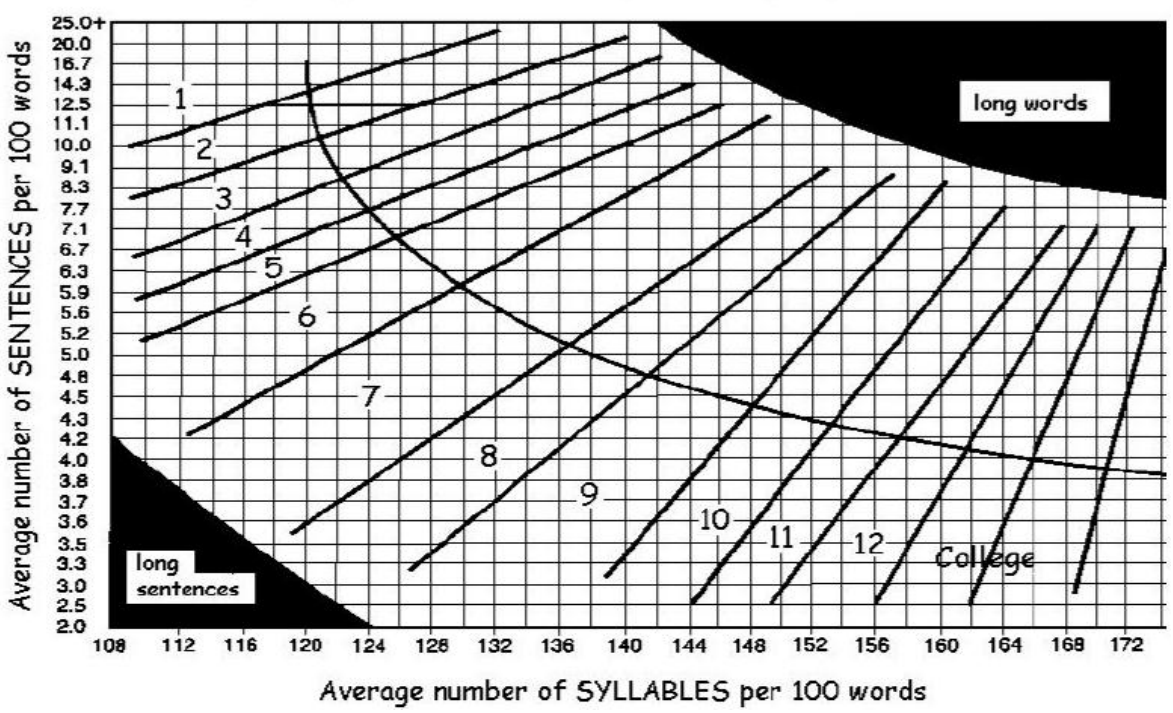

Figure 1. Fry"'s Readability Chart (Adapted from school.discoveryeducation.com)

\subsection{Procedural Accessibility}

Procedural accessibility within this study refers to the availability of data collection techniques which could accommodate the needs of potential participants. The procedural accessibility was assessed through the provision of different social mediums for participation in the study: face-to-face, via telephone or Skype, via email or any combination. All the pilot study participants reviewed the options for participation and decided independently which one suited them best. For instance, some people with moderate to severe cerebral palsy may have difficulty with oral communication and an interview guide sent via e-mail to be would be more appropriate. Participants were also offered a telephone interview if transportation was difficult to arrange or if they preferred to stay at home. One of the participants chose this method and felt it provided him with access to participation and accommodated his schedule. It can be projected then, that the participants of the main study will understand and be able to make a choice best suited to their preferences.

The provision of accessible options for participation allowed individuals to be involved in whatever setting(s) they felt suited them best. In addition, participants who felt fatigued or distressed and who wanted to continue participating in the study were provided the option of being interviewed over two sessions or more sessions. Two of the pilot study participants completed the interview in one face-to-face sitting while the third participant chose to do the interview over the phone in two portions due to fatigue. Participants were also advised that they were welcome to enlist the aid of communication devices, translators or other aids if they felt that they wanted or needed to. Ultimately, procedural access to the interview had been achieved as participants were provided with a multitude of ways to be part of the study.

\section{Assessing Trustworthiness of the Interview Guide}

Four issues which contribute to trustworthiness were piloted: credibility, transferability, dependability, and confirmability. The procedures are discussed below.

\subsection{Assessing Credibility}

The study was premised upon the assumption that people with cerebral palsy, in their general understanding of sexuality, would describe it in terms that parallel or mirror private, interactional and public sexual constructs. As such, a goal of the pilot study was to determine the credibility of these constructs. To tackle the issue of credibility "member checking" (Lincoln \& Guba, 1985) with all three of the pilot study participants was conducted. In the process of member checking, each of the research participants was asked questions via telephone (see Table 3 for member checking telephone script) to ascertain whether or not the use of private, interactional and public conceptualizations of sexuality were credible constructs for this study. The following script (Table 3) which included questions and probes was used to gauge the presence of public, interactional and private constructs in participants' conceptualizations of sexuality. 
Table 3. Credibility of Public, Interactional and Private Constructs Member Checking Script

\begin{tabular}{|l|r|}
\hline & Question s'Discussion: \\
\hline Introduction: & $\begin{array}{r}\text { Some people would say that a person's sexuality is made up of a variety of different things. I'd like to ask you a few questions about some of the ways } \\
\text { that people think about sex. }\end{array}$ \\
\hline Grand Tour: & $\begin{array}{r}\text { Tell me about your views about sexuality. } \\
\text { Tell me what comes to mind. } \\
\text { There is no importance to what comes first. } \\
\text { a) If participant generates concepts, probe concepts } \\
\text { b) If they feel differently ask them why. }\end{array}$ \\
\hline Private: & $\begin{array}{r}\text { Generally sexuality and sexual activities are considered private things. What do you think about that? } \\
\text { a. If participant generates concepts, probe concepts } \\
\text { b. If they feel differently ask them why. }\end{array}$ \\
\hline Interactional: & $\begin{array}{r}\text { When people think about sex they may often think about having sexual experiences with another person or people. What do you think that means? } \\
\text { a. If participant generates concepts, probe concepts } \\
\text { b. If they feel differently ask them why. }\end{array}$ \\
\hline Public: & $\begin{array}{r}\text { The media presents a lot of information about sex. How do you think that could influence sexuality? } \\
\text { a. If participant generates concepts, probe concepts } \\
\text { b. If they feel differently ask them why. }\end{array}$ \\
\hline
\end{tabular}

6.1.1 Member checking Results

All participants surveyed felt that sexuality was made up of many different factors (see Table 4). They further confirmed that while spaces for experiences of sexuality are commonly considered "private" (i.e., in the privacy of one's home or "behind closed doors") the initiation of sexual encounters was personal. In addition, participants felt that part of a satisfactory sex life included being able to share ones sexuality with others. This included exploring sexual options and activities with different people and settings in order to discover what they really wanted from intimate relationships.

Finally, all the participants mentioned that they had fantasized about a celebrity or a friend who resembled a media personality when they engaged in sexual activities with themselves and sometimes with others. The participants explained that the media tells people how to deal with sex as well as who and what is sexy. In addition, all three participants made comments that directly connected private, interactional and public sexual constructs to one or more personal experiences they had in the past. This feedback suggests that private, public and interactional sexual constructs may be natural to the discourse of people with cerebral palsy in understanding their sexuality.

Table 4. Credibility of Public, Interactional and Private Constructs Member Checking Results Summary

\begin{tabular}{|c|c|c|c|}
\hline Participant & Private Construct of Sexuality & Interactional Construct of Sexuality & Public Construct of Sexuality \\
\hline Participant 1 & $\begin{array}{l}\text { "...sex, like intercourse, isn't something that I'd do } \\
\text { with anybody, anywhere... I mean, like I'd do it at } \\
\text { home. Like, it doesn't have to be in the bedroom or in } \\
\text { the bed for that matter but in my own space...I'd feel } \\
\text { more comfortable". }\end{array}$ & $\begin{array}{l}\text { "Sex is intimate, like not just with yourself, I mean it } \\
\text { is in that respect, but I mean like it is } \\
\text { connecting ... connective... with someone else... Not } \\
\text { that having 'sex' with yourself isn't fun or satisfying } \\
\text { but doing it with someone else is even better. Like, it } \\
\text { reinforces that you are sexy, deserve sex or like you } \\
\text { are what or who someone thinks is worthy of 'gettin' } \\
\text { jiggy with". }\end{array}$ & $\begin{array}{l}\text { "I mean who doesn't like a good looking body or } \\
\text { person. I mean there are so many good looking } \\
\text { people, like sometimes it doesn't have anything to do } \\
\text { with disability or anything but when they have the } \\
\text { features you know? Those things that make someone } \\
\text { sexy... I mean it's hard I'm sure for anyone to resist } \\
\text { that." }\end{array}$ \\
\hline Participant 2 & $\begin{array}{l}\text { "I mean look, I don't necessarily 'get it on' on a daily } \\
\text { basis, physically I mean, but I don't need that } \\
\text { either... Look, sometimes it's nice just to think about } \\
\text { it, fantasize without anything physical happening. It } \\
\text { gets you going, you know?" }\end{array}$ & $\begin{array}{l}\text { "Part of me, my sexuality I mean, is made up of } \\
\text { trying, the ability, the desire you know, to try out } \\
\text { different things and different people. Like you don't } \\
\text { have to have 'sex-sex' but being with different } \\
\text { people sensually kind of is like exploring my sexual } \\
\text { side... figuring it out you know?" }\end{array}$ & $\begin{array}{l}\text { "Jennifer Hawkins, that's right everybody knows } \\
\text { who she is...But I guess I'm a red-blooded male. Any } \\
\text { pretty face that smiles at you...Particularly if they're } \\
\text { long legged and absolutely gorgeous. You know } \\
\text { Donald Trump even seems to think that the sunlight } \\
\text { shines out of her every orifice, which it does. And } \\
\text { look, to add to the mix, with someone like that, it's } \\
\text { really the first time you fall in love although you } \\
\text { don't really know it". }\end{array}$ \\
\hline Participant 3 & $\begin{array}{l}\text { "I feel like, when I'm having fun, like having sexual } \\
\text { type fun with myself or someone else it's just more } \\
\text { fun when you think of something or the other person } \\
\text { as everything you want... why not right? I mean it's } \\
\text { my head, I can think of whatever I want". }\end{array}$ & $\begin{array}{l}\text { "The best part of sex, or doing sexy stuff, with other } \\
\text { people is the look on their face. I mean like, you } \\
\text { know that look when you know someone is having a } \\
\text { good time? Like for me, I suspect for everyone that is } \\
\text { like the goal, like to please, satisy the person you're } \\
\text { doing sexy stuff with". }\end{array}$ & $\begin{array}{l}\text { "I mean if you have experiences that aren't what } \\
\text { people think is right then that can put a damper on } \\
\text { things a bit... I mean it's ruined by what other people } \\
\text { think is supposed to happen for men or women or } \\
\text { whatever...I mean in that respect things can get } \\
\text { confusing because you not doing what 'you're } \\
\text { supposed to' even though it makes you happy." }\end{array}$ \\
\hline
\end{tabular}

\subsection{Assessing Transferability}

Transferability pertains to the potential for this study's finding to transfer to other settings and/or populations. Transferability was achieved as the findings from the pilot study mirror those of similar nature in other studies (i.e., Taleporos \& McCabe, 2001, 2002, 2003, 2005) which explored constructions of sexuality (i.e., sexual esteem, sexual 
satisfaction, sexual ideation(s)) by and within people with cerebral palsy and other physical disabilities. In this regard, public, interactional and private constructions of sexuality and disability have been indicated both in this pilot study and relevant research (i.e., Shakespeare, 1996, 2000, 2007; Tepper, 1999, 2000) as salient to experiences of sexuality and the self for people with physical disabilities. As such, it can be expected that the findings from the pilot study can be transferred to the participants of the main study as they share many of the same developmental experiences and/or qualities.

In addition, a number of the data analyses done through NVivo 9 software and line-by-line analysis, were used to help answer the research questions and formulate a new Model for the Construction of Individual Sexuality in People with Cerebral Palsy. Transferability of this study's protocol was also achieved through making these documents available upon request. Providing evidence of the analytic process allows other researchers to repeat, as closely as possible the procedures of this project. In addition, other researchers can utilize the study procedures to analyze data from research which explores similar concepts. In this way transferability can be accessed and assessed by other research and researchers.

\subsection{Assessing Dependability and Confirmability}

As mentioned, reviewing the dependability of one's research is an assessment of the quality of data collection, analysis, and theory production. Confirmability is a measure of the level to which the study's findings are supported by the collected data (Tipping, Scholes \& Cox, 2010). To enhance the dependability and confirmability of the study, an independent audit of my research methods by a competent peer (Lincoln \& Guba, 1985; Patton, 2001) was sought. As such, the independent auditor must review all documents in order to make an assessment of on whether or not the study and its conclusions followed a logical progression through the chain of evidence (Smith, 2003).

Yin (2010) suggested that one way of checking the trustworthiness of one's research report is to file all the data in such a way that allows others to follow the chain of evidence that has led to the final report. Part of this chain may include initial notes on the research question(s), interview schedule, digital audio files, annotated transcripts, codings and initial categorizations, draft reports and final reports. Subsequently, the file of material is given to an associate researcher who played no part in the study.

The auditor of this project, Dr Nicole Hartman (not real name), is a practicing occupational therapist in the field of disability and sexuality whose "hands-on" experience with disability parallels some of those of the researcher. At the time this study was being conducted she was also in the process of finishing her own Ph.D. in the Faculty of Health Sciences, Sexual Health Unit and is quite familiar with qualitative research methodologies.

Upon completion of the data analysis for this project and the majority of writing for the Results and Discussion chapters, Dr Hartman examined the audit trail which included; initial notes on the research question, original transcripts, data analysis documents, line-by-line coding, comments from the member checking process, and the text of the thesis itself. In doing so the auditor assessed both the dependability and confirmability of the study, as well as the completeness and availability of auditable documents. She further assessed the degree and significance of researcher influence through the examination of verbatim transcripts.

\section{Discussion: Key Lessons from the Pilot Study}

Consistent with the aims of the pilot study networks were established which facilitated recruitment of individuals within the sampling frame and also provided participants for the main study. However, relatively few participants were projected by agencies to as likely to participate in the study in Australia. While participation in the pilot study may have been limited it was still accessible. The interview guide's readability (grade 5 to 7 ) level meant that all participants were likely to understand the questions. All participants found that the majority of the interview guide was easy to understand and answer. Further, the pilot study confirmed that the interview guide could be accessed by many people in the sampling frame as it was adaptable to different media and social formats. It also met common standards for cognitive and procedural accessibility.

The trustworthiness of the study was confirmed through an assessment of the credibility, transferability, dependability and confirmability of the interview guide. Credibility was achieved during the member checking process as participants of the pilot study spontaneously and naturally used terms consistent with private, interactional and public sexual constructs included in the interview guide.

Transferability was achieved through the provision of evidence of the analytic process which may allow other researchers to repeat, as closely as possible the procedures of this project. Alternatively other researcher may utilize the procedures indicated within this study to analyze data from research which explores similar concepts

Dependability and confirmability of the data collection, analysis, theory production and the level to which the study's findings are supported by the collected data were ensured through the employment of an independent audit of the 
research methods by a competent peer.

Through the process of conducting the pilot study only minor changes to the interview guide or analytic process were made. For example, an international sample was sought for the main study (through the Attendant Care Program in Ottawa, Ontario, Canada) in order to boost the level of participation. In this respect future recruitment efforts may be more successful if the researcher was a trusted member of the communities in which people with Cerebral Palsy (or disabilities in general) exist.

In addition, minor additions and modifications to some of the interview guide questions were made in order to increase clarity and reduce confusion about questions which the researcher and her peers felt may have been complicated concepts. From these results the main study design was adapted (see Figure 2).

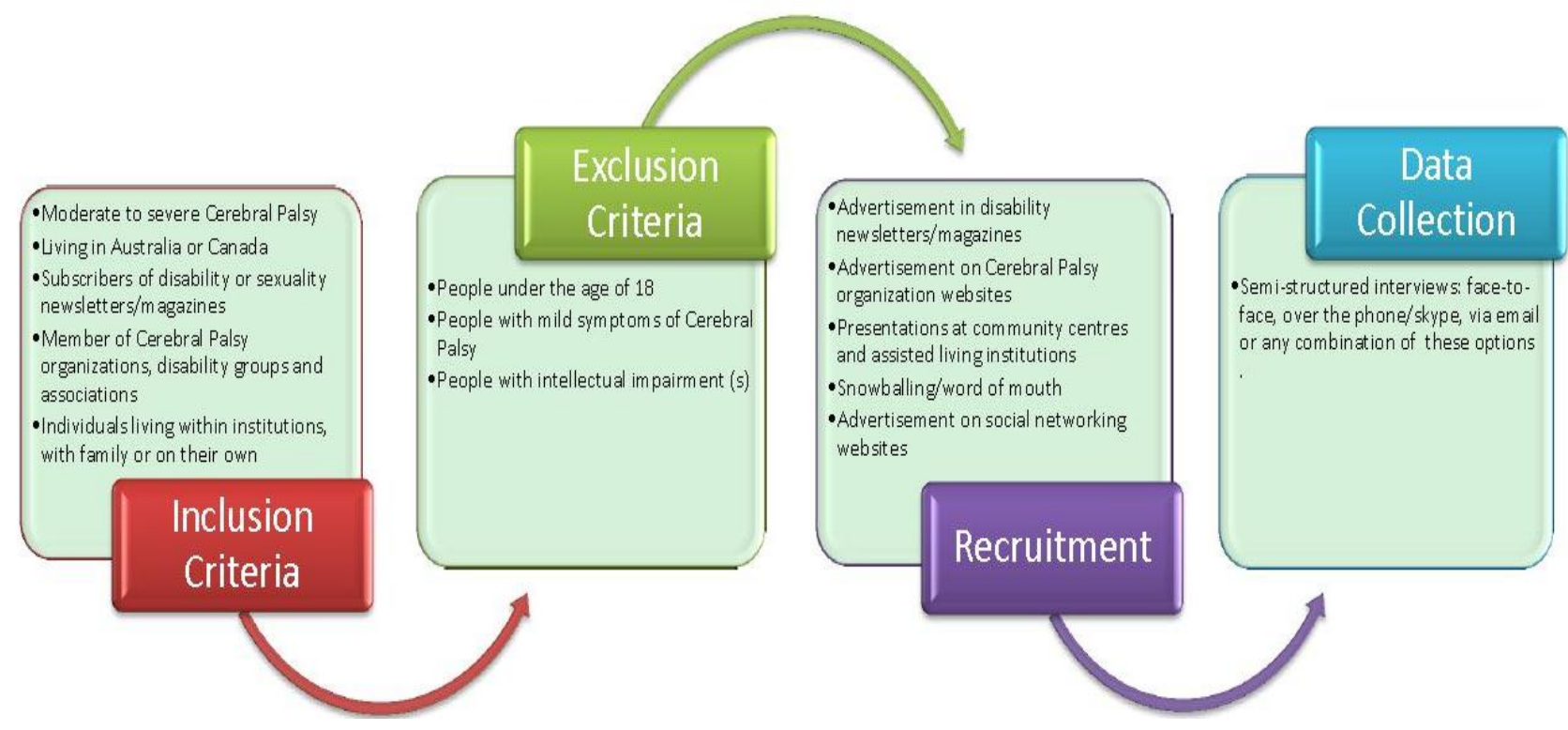

Figure 2. Main Study Design Flowchart

\section{Conclusion}

This study used person-oriented measures to investigate insider perspectives of cerebral palsy. Primarily the research explored how they construct their sexuality and the factors that influence that process. To this end, the pilot study established and confirmed that the proposed networks were viable for the recruitment of participants for the main study. In line with the expectations of qualitative research, the trustworthiness of the study was affirmed through an assessment of the credibility, transferability, dependability and confirmability of the interview guide. Summarily, transferability was achieved through the provision of evidence of the analytic process which may allow other researchers to repeat, as closely as possible the procedures of this project. Dependability and confirmability of the data collection, analysis, theory production and the level to which the study's findings are supported by the collected data were ensured through the employment of an independent audit of the research methods by a competent peer.

This pilot study demonstrated that when considering engaging in research with population cohorts which are hidden or excluded from the mainstream it may be difficult to ascertain if one's recruitment methods will first of all yield participants. Further, due to limited research in the area of sexuality and cerebral palsy the data collection techniques and measures that one uses to explore their desired areas of interest are unclear. As such, pilot studies are especially useful in the study of sexuality and disability as they can provide the means to establish recruitment networks, test measures and facilitate ameliorations to research design.

Pilot studies continue to be a medium to test research methodology and apply necessary amendments in order to conduct larger studies. Fundamentally, establishing research foundations within this field is imperative if people with disability are to be acknowledged as sexual agents and beings that have much to say for themselves about how they have and would like to engage with their sexualities.

\section{References}

Ajjawi, R., \& Higgs, J. (2007). Using hermeneutic phenomenology to investigate how experienced practitioners learn to communicate clinical reasoning. The Qualitative Report, 12(4), 612-638. 
Brown, D. E. (1988). Factors affecting psychosexual development of adults with congenital physical disabilities. Physical \& Occupational Therapy in Pediatrics, 8(2-3), 43-58. http://dx.doi.org/10.1080/J006v08n02_03

Chance, R. S. (2002). To love and be loved: Sexuality and people with physical disabilities. Journal of Psychology and Theology, 30.

Dune, T. M. (2014a). Conceptualizing Sex with Cerebral Palsy: A Phenomenological Exploration of Private Constructions of Sexuality using Sexual Script Theory. International Journal of Social Science Studies, 2(2), 20-40. http://dx.doi.org/10.11114/ijsss.v2i2.287

Dune, T. M. (2014b). You just don't see us: The influence of public schema on constructions of sexuality by people with cerebral palsy. World Journal of Social Science, 1(1), 1-19.

Dune, T. M. (2013). Re/Developing Models for Understanding Sexuality with Disability within Rehabilitation Counselling. Electronic Journal of Human Sexuality, 16(April).

Dune, T. M., \& Shuttleworth, R. P. (2009). It's Just Supposed to Happen: The Myth of Sexual Spontaneity and the Sexually Marginalized. Sexuality and Disability, 27(2), 97-108. http://dx.doi.org/10.1007/s11195-009-9119-y

Earle, S. (1999). Facilitated sex and the concept of sexual need: disabled students and their personal assistants. Disability and Society, 14, 309-323. http://dx.doi.org/10.1080/09687599926163

Fry, E. (1968). A readability formula that saves time. Journal of Reading, 11(7), 513-516, 575-578.

Hoffman, R. M. (2010). Editorial: Trustworthiness, credibility, and soundness: A vision for research in the Journal of Mental Health Counseling. Journal of Mental Health Counselling, 32(4), 283-287. http://dx.doi.org/10.17744/mehc.32.4.1147q4w7j26j3422

Joseph, R. (1991). A case analysis in human sexuality: Counseling to a man with severe cerebral palsy. Sexuality and Disability, 9(2), 149-159. http://dx.doi.org/10.1007/BF01101740

Liamputtong, P. (2010). Performing qualitative cross-cultural research. Cambridge: Cambridge University Press. http://dx.doi.org/10.1017/CBO9780511812705

Lincoln, Y. S., \& Guba, E. G. (1985). Naturalistic inquiry. London: Sage.

Mayoux, L. (2006). Quantitative, qualitative or participatory? Which method, for what and when? In V. Desai, \& R. B. Potter, Doing Development Research, 113-129.

McCarthy, M. (2010). What kind of a future for young people with Down's Syndrome? The views and aspirations of young people and families. Tizard Learning Disability Review, 15(4), 30-33. http://dx.doi.org/10.5042/tldr.2010.0591

Ompad, D. C., Galea, S., Marshall, G., Fuller, C. M., Weiss, L., Beard, J. R., et al. (2008). Sampling and recruitment in multilevel studies among marginalized urban populations: The IMPACT studies. Journal of Urban Health, 85 (2), 268-280.

http://dx.doi.org/10.1007/s11524-008-9256-0

Palisano, R., Rosenbaum, P., Walter, S., Russell, D., Wood, E., \&Galuppi, B. (1997). Development and reliability of a system to classify gross motor function in children with cerebral palsy. Developmental Medicine \& Child Neurology, 39(4), 214-223. http://dx.doi.org/10.1111/j.1469-8749.1997.tb07414.x

Patton, M. Q. (2001). Two decades of developments in qualitative inquiry. Qualitative Social Work, 1(3), 261-283. http://dx.doi.org/10.1177/1473325002001003636

Rhodes, S. A., Bowie, D. A., \& Hergenrather, K. C. (2003). Collecting behavioural data using the world wide web: Considerations for researchers. Journal of Epidemiology and Community Health, 57(1), 69-73. http://dx.doi.org/10.1136/jech.57.1.68

Sanders, T. (2007). The politics of sexual citizenship: Commercial sex and disability. Disability and Society, 22(5), 439-455. http://dx.doi.org/10.1080/09687590701427479

Shakespeare, T. (1996). Disability, identity and difference. In G. M. Colin Barnes, Exploring the Divide, 94 -113.

Shakespeare, T. (2000). Disabled sexuality: Toward rights and recognition. Sexuality and Disability, 18(3), 159-166. http://dx.doi.org/10.1023/A:1026409613684

Shakespeare, T. (2007). Rules of engagement: Changing disability research. In L. Barton, \& M. Oliver, Disability studies: past, present and future, 217-233.

Silverman, D. (2009). Doing qualitative research. London: Sage. 
Simon, W., \& Gagnon, J. H. (1986). Sexual scripts: Permanence and change. Archives of Sexual Behaviours, 15(2), 97-120. http://dx.doi.org/10.1007/BF01542219

Simon, W., \& Gagnon, J. H. (1987). A sexual scripts approach. In J. H. Geer, \& W. T. O'Donohue, Theories of human sexuality, 363-383.

Simon, W., \& Gagnon, J. H. (2003). Sexual scripts: Origins, influences and changes. Qualitative Sociology, 26(4), 491-497. http://dx.doi.org/10.1023/B:QUAS.0000005053.99846.e5

Smith, R. (2003). Audit Committees: Combined Code Guidance. London: Financial Reporting Council.

Stevens, E., Steele, C. A., Jutai, J. W., Kalnins, I. V., Bortolussi, J. A., \&Biggar, D. (1996). Adolescents with physical disabilities: Some psychosocial aspects of health. Journal of Adolescent Health, 19(2), 157-164. http://dx.doi.org/10.1016/1054-139X(96)00027-4

Taleporos, G., \& McCabe, M. (2001). Physical disability and sexual esteem. Sexuality and Disability, 19, 131-148. http://dx.doi.org/10.1023/A:1010677823338

Taleporos, G., \& McCabe, M. (2002). Development and validation of the physical disability sexual and body esteem scale. Sexuality and Disability, 20, 159-176. http://dx.doi.org/10.1023/A:1021441631385

Taleporos, G., \& McCabe, M. (2003). Relationships, sexuality and adjustment among people with physical disability. Sexuality and Disability, 18, 5-6.

Taleporos, G., \& McCabe, M. (2005). The relationship between the severity and duration of physical disability and body esteem. Psychology and Health, 20(5), 637-650. http://dx.doi.org/10.1080/0887044042000334733

Taleporos, G., \& McCabe, M. (2005). The relationship between the severity and duration of physical disability and body esteem. Psychology and Health, 20(5), 637-650. (i.e., Taleporos\& McCabe, 2001, http://dx.doi.org/10.1080/0887044042000334733

Tepper, M. S. (1999). Letting go of restrictive notions of manhood: Male sexuality, disability and chronic illness. Sexuality and Disability, 17(1), 37-52. http://dx.doi.org/10.1023/A:1021451712988

Tepper, M. S. (2000). Sexuality and disability: The missing discourse of pleasure. Sexuality and Disability, 18(4), 283-290. http://dx.doi.org/10.1023/A:1005698311392

Tipping, C. J., Scholes, R. L., \& Cox, N. S. (2010). A qualitative study of physiotherapy education for parents of toddlers with cystic fibrosis. Journal of Cystic Fibrosis, 9(3), 205-211. http://dx.doi.org/10.1016/j.jcf.2010.02.003

Van Teijlingen, E. R., Rennie, A. M., Hundley, V., \& Graham, W. (2001). The importance of conducting and reporting pilot studies: the example of the Scottish Births Survey. Journal of Advanced Nursing, 34(3), 289-295. http://dx.doi.org/10.1046/j.1365-2648.2001.01757.x

Van-Manen, M. (2002). Writing in the dark: Phenomenological studies in interpretive inquiry. London: Althouse. .

Wiwanitkit, V. (2008). Sexuality and rehabilitation for individuals with cerebral palsy. Sexuality and Disability, 26(3), 175-177. http://dx.doi.org/10.1007/s11195-008-9088-6

Yin, R. K. (2010). Qualitative research from start to finish. New York: Guilford Press.

Xenakis, N., \& Goldberg, J. (2010). The young women's program: A health and wellness model to empower adolescents with physical disabilities. Disability and Health Journal, 3(2), 125-129.

http://dx.doi.org/10.1016/j.dhjo.2009.08.001

\section{(cc) $\mathrm{BY}$}

This work is licensed under a Creative Commons Attribution 3.0 License. 